\title{
Grain size characterization of instream sand deposition in controlled environment in river Kangsabati, West Bengal
}

\author{
Raj Kumar Bhattacharya ${ }^{1}$ (i) $\cdot$ Nilanjana Das Chatterjee $^{1} \cdot$ Gour Dolui $^{1}$
}

Received: 25 April 2016/ Accepted: 4 June 2016/Published online: 25 June 2016

(C) Springer International Publishing Switzerland 2016

\begin{abstract}
Channel morphology is triggered by transport capacity, velocity of water, volume and size of the supplied sediment. Changes in grain size, critical shear stress and bed roughness can increase transport capacity in response to high sediment supply where anthropogenic factors become important for fluvial dynamics through removal of bed materials. In a stable sand feeding condition, sediment transport may gradually increase towards river bed due to the increasing shear stress. When the sediments are removed naturally or anthroprogenically from river bed, sand feeding condition gets interrupted and generate hungry water. It also reduces the shear stress on convex slope. This situation creates an environment of sand-gravel mixture. This study aims to find out the relationship between grain size and bed shear stress in normal condition and depositional changes due to human intervention. Present research work has been conducted on three selected mining spots from three courses of Kangsabati River i.e. Sarenga (upper course), Mohanpur (middle course) and Palaspai (lower course), respectively. DuBoys equation and Shields formula (1936) has been taken to explain the mechanisms of shear stress and critical shear stress in connection to the course wise variation of the transport capacity of sediment in different mining and non-mining sites. Flow velocity was measured by floating method. Textural analysis of
\end{abstract}

Electronic supplementary material The online version of this article (doi: 10.1007/s40808-016-0173-z) contains supplementary material, which is available to authorized users.

\section{Raj Kumar Bhattacharya}

rajgeovu10@gmail.com

1 Department of Geography and Environment Management, Vidyasagar University, Midnapore 721102, West Bengal, India collected sediments was measured by sieve technique and GRADISTAT is used to determine the mean, shorting, peakness and skewness and G-STAT is used for CM and triangular diagrams of the grain size distribution. Result shows that critical shear stress is higher in Sarenga and gradually decreases towards Mohanpur and Palaspai. So, sediment erosion highly occurs in the upper portion of the basin and relatively lowers in lower course. Grain size distribution reveals that most of sediments are coarse in nature, well sorted and very leptokurtic in Sarenga while in Palaspai sand is medium sized, moderate well sorted and mesokurtic in nature. The coarse sediments are deposited by higher threshold value of bed mobility in Sarenga while medium particles are deposited due to lower threshold value in Mohanpur and Palaspai.

Keywords Sand feeding · Hungry water - Critical shear stress $\cdot$ Bed mobility

\section{Introduction}

Grain size studies on instream sediments give details information of the interior properties of sediment discharge and depositional environment (Folk and Ward 1957; Friedman 1979; Martins 1965). Further, they imply flow resistance by altering the hydraulic characteristics near the bed of the channel (Leopold 1992; Jain and Kothyari 2009). Various physical factors i.e. sediment transport, sediment aggregation and deposition, gravitational circulation played significant role to grain size distribution (Wai et al. 2004). High energy flow regime clog up coarser sediments while finer sediments found in low energy environment (Folk 1966; Friedman 1962, 1967; Moiola and Weiser 1968). Generally, river 
sediments segregated into two type of texture i.e. sandy silt and coarse grained, whereas in estuary system sediments are clayey silt and fine grained (Nair and Ramachndran 2002). The grain size distribution is believed to be considered as several normal sub-populations representing the sediments transported by the process of rolling, saltation and suspension (Inaman 1952). Several factors are strongly influence on textural attributes of sediments. They are source area composition of adjacent lands, climate, length and energy of sediment transport and redox conditions in the depositional environment (Bhatia and Crook 1986; Fralick and Kronberg 1997). Textural attributes of sediments like, Mean (Mz), standard deviation (ó1), skewness (SK1), and kurtosis (KG) are widely used to reconstruct the depositional environment of sediments and sedimentary rocks (Komar 1998; Poppe and Elison 2007). They have correlation between size parameters and transport processes/depositional mechanism of sediments. This relationship has been established by careful studies in many modern and ancient sedimentary environments (Folk and Ward 1957; Friedman 1962, 1967; Visher 1969; Al-Saleh and Khalaf 1982; Asselman 1999; Angusamy and Rajamanickam 2006). Study on various sand deposition environment found that when skewness of distribution was plotted against mean size ( $\varphi$ value), the dune sands, ocean beach sands and the lake sands presents a clear complete separation. Friedman (1962) and Moiola and Weiser (1968) pointed out that kurtosis and skewness of a given sediment sample when plotted against each other is an efficient tool to differentiate the deposition character of sediments.

Entrainment of sediment is occurs when shear stress has exceeds of the critical shear stress. It could potentially effects erosion of channel bed or banks (Buffington and Montgomery 1997; Church 2006; Charlton 2007). DuBoys equation helps to determine boundary shear stress. Shear stress exerted on the channel bed as water moves down to increase flow depth and channel steepness (Mueller et al. 2005; Church 2006). Shelting, imbrications, armoring, and other sorting processes in turn controlled by critical shear

Table 1 Salient features of this river basin area (West Bengal Annual flood report 2013)

\begin{tabular}{llll}
\hline Salient features & Upper course & Middle course & Lower course \\
\hline Channel braiding $(\mathrm{SI})$ & $<1.3$ & $<1.5$ & $<2.0$ \\
Basin area $\left(\mathrm{km}^{2}\right)$ & 3562 & 4213 & 1883 \\
River length $(\mathrm{km})$ & 141 & 150 & 150 \\
Gauge height in m GTS (monsoon season) & 26.2 & 16.6 & 10.6 \\
\hline
\end{tabular}

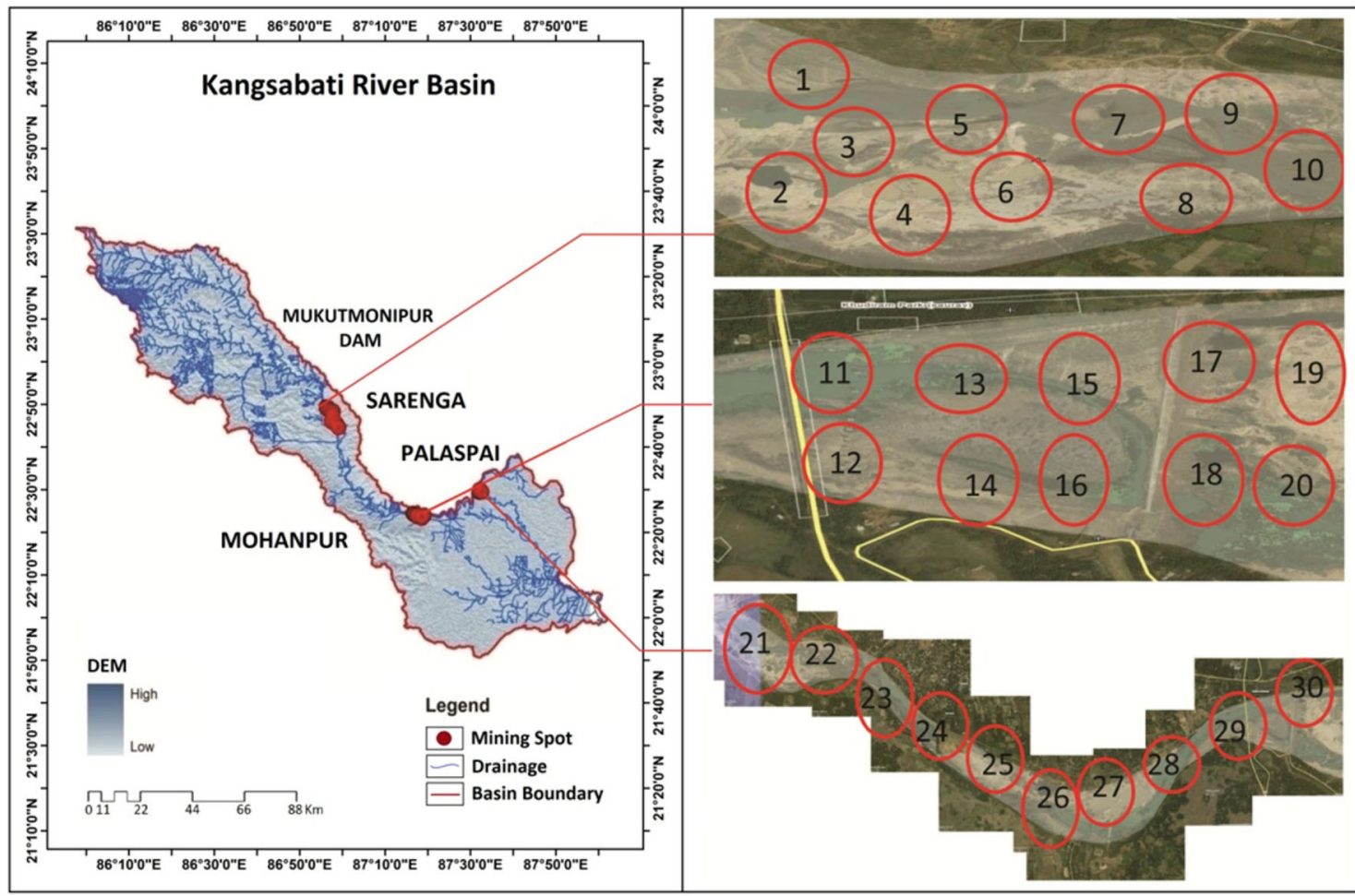

Fig. 1 Location map of the study area 

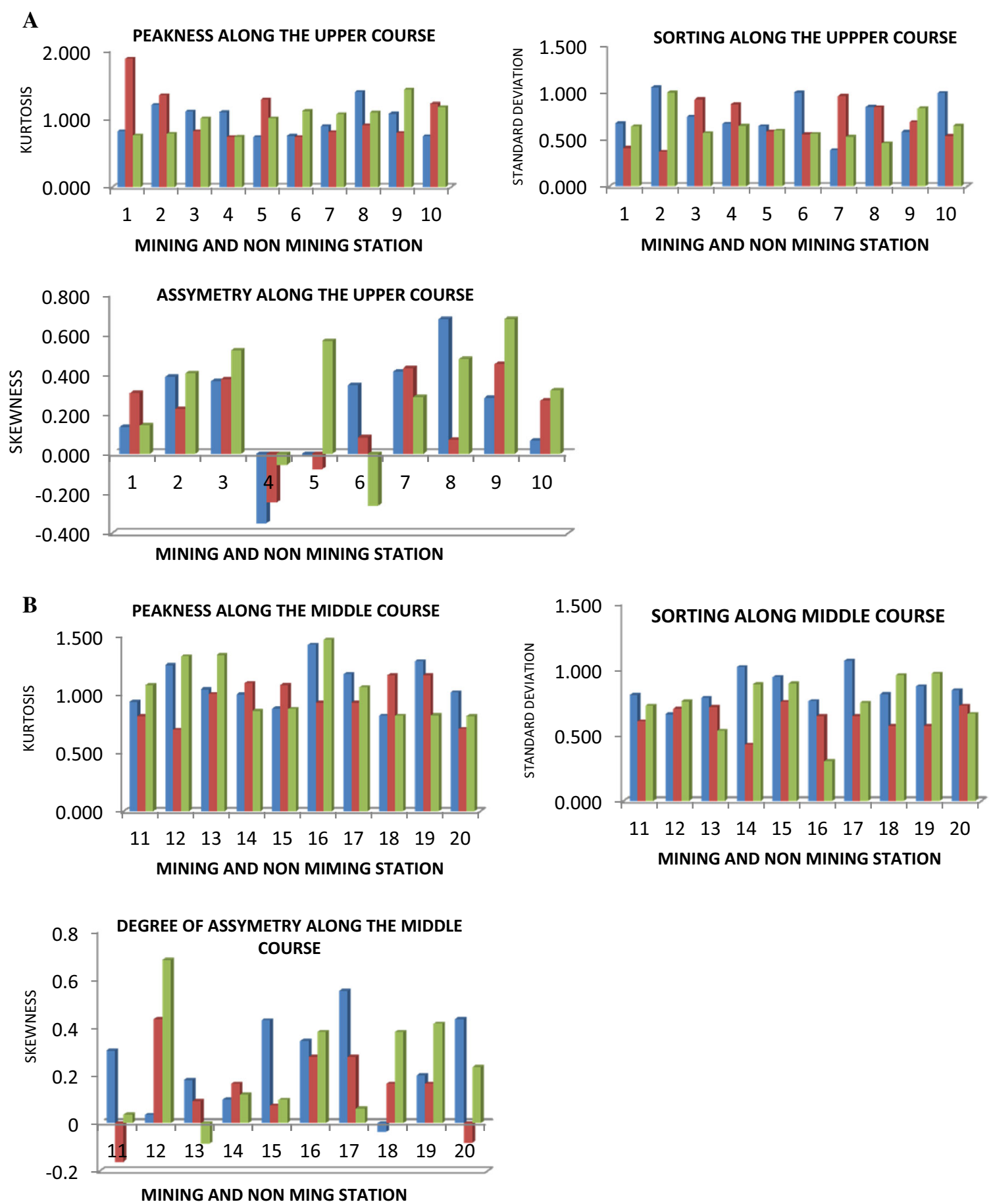

Fig. 2 a Average values of grain size statistical parameters in Sarenga: kurtosis; sorting; skewness during pre-monsoon,monsoon and post-monsoon. b Kurtosis, sorting and skewness in Mohanpur

during pre-monsoon,monsoon and post-monsoon. c Kurtosis, sorting and skewness in palaspai during pre-monsoon, monsoon and postmonsoon

stress (Charlton 2007; Clayton 2010). Friction angle changes with the size of the grains and it requires higher critical shear stress to be entrained (Wiberg and Smith 1987). Sediment sorting a poorly sorted substrate having heterogeneous grains shows high resistance across the channel bed, while a well-sorted substrate having homogenous grains showing low resistance across the channel (Mueller et al. 2005). Similar situation have been identified in Kangsabati River in West Bengal. Therefore, the present study attempts have been made to explain the available shear stress in different course of the stream during pre-monsoon and monsoon. 

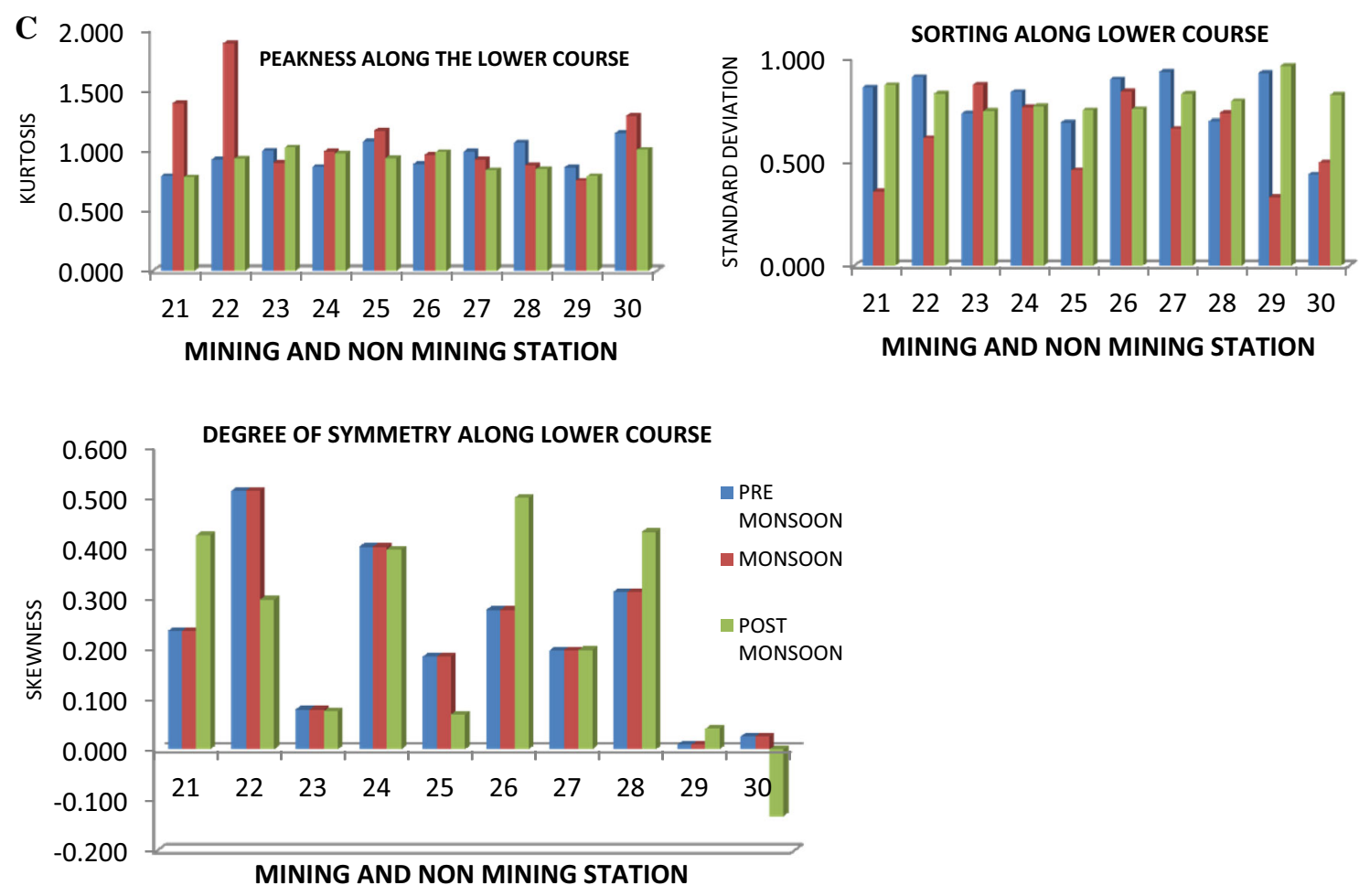

Fig. 2 continued

\section{Study area}

Kangsabati River (also variously known as the Kasai, Kansai and Cossye) originated from the Chotanagpur plateau in the state of Jharkhand, India and passes through the districts of Purulia, Bankura and Paschim Midnapore of West Bengal. This river basin is bounded by latitude $21^{\circ} 45^{\prime} \mathrm{N}$ to $23^{\circ} 30^{\prime} \mathrm{N}$ and longitude $85^{\circ} 45^{\prime} \mathrm{E}$ to $88^{\circ} 15^{\prime} \mathrm{E}$. The basin covers an area of about $9658 \mathrm{~km}^{2}$. The entire Kangsabati River has been divided into three courses. The upper course is extended between Jhaldia and Sarenga, middle course extended between Sarenga and Mohanpur and lower course lies from Mohanpur to Bandar near Ghatal (Rupnaryan branch). The sampling location has been carried out for every $500 \mathrm{~m}$ (approximately) out of each course, respectively (Table 1; Fig. 1). This alluvial river exhibits dendritic to subdendritic drainage pattern. The basin is segregated on the basis of physiographic divisions into six divisions; three comes under the study area. Geologically the study area is constituted by various stratigraphic units, ranging from the oldest Archaeans (pre-Cambrian) to the younger Tertiary-Quaternary formations (Mukhopadhyay 1992). Land use types are distinctly governed by physiographic and climatic characteristics with natural and planted forest. The present investigation is confined to course wise three physiographic regions because naturally deposited sands are extracted from instream and floodplain areas leading to irregular changes in the river bed.

\section{Materials and method}

90 sediment samples including 10 (pre monsoon), 10 (monsoon) and 10 (post monsoon) from each station were collected. The samples were repeatedly washed, dried and thoroughly mixed. By successive coning and quartering on a piece of paper a specific weight about $50 \mathrm{gm}$ was taken for analysis. Dry samples were placed in the uppermost sieve and covered in a set of stacked sieves $(16 \emptyset-1 \varnothing)$. The set of sieves was then placed on standard ASTM Erode colt sieve at half phi intervals. The sample was then sieved for 15 min in ro-top mechanical sieve shaker using a standard ASTM Erode colt sieve. The sand that remained on each sieve and pan was collected and weighted using a digital balance having an accuracy of $0.0001 \mathrm{gm}$. Mean (MZ), Sorting (ó 1), Skewness (SK1) and Kurtosis (KG) of the sediment distribution were measured by GRADISTAT. The grain size parameters like frequency curves scatter plots, triangular and CM diagram were drawn and analyzed by G-Stat software (Dinesh 2009). 

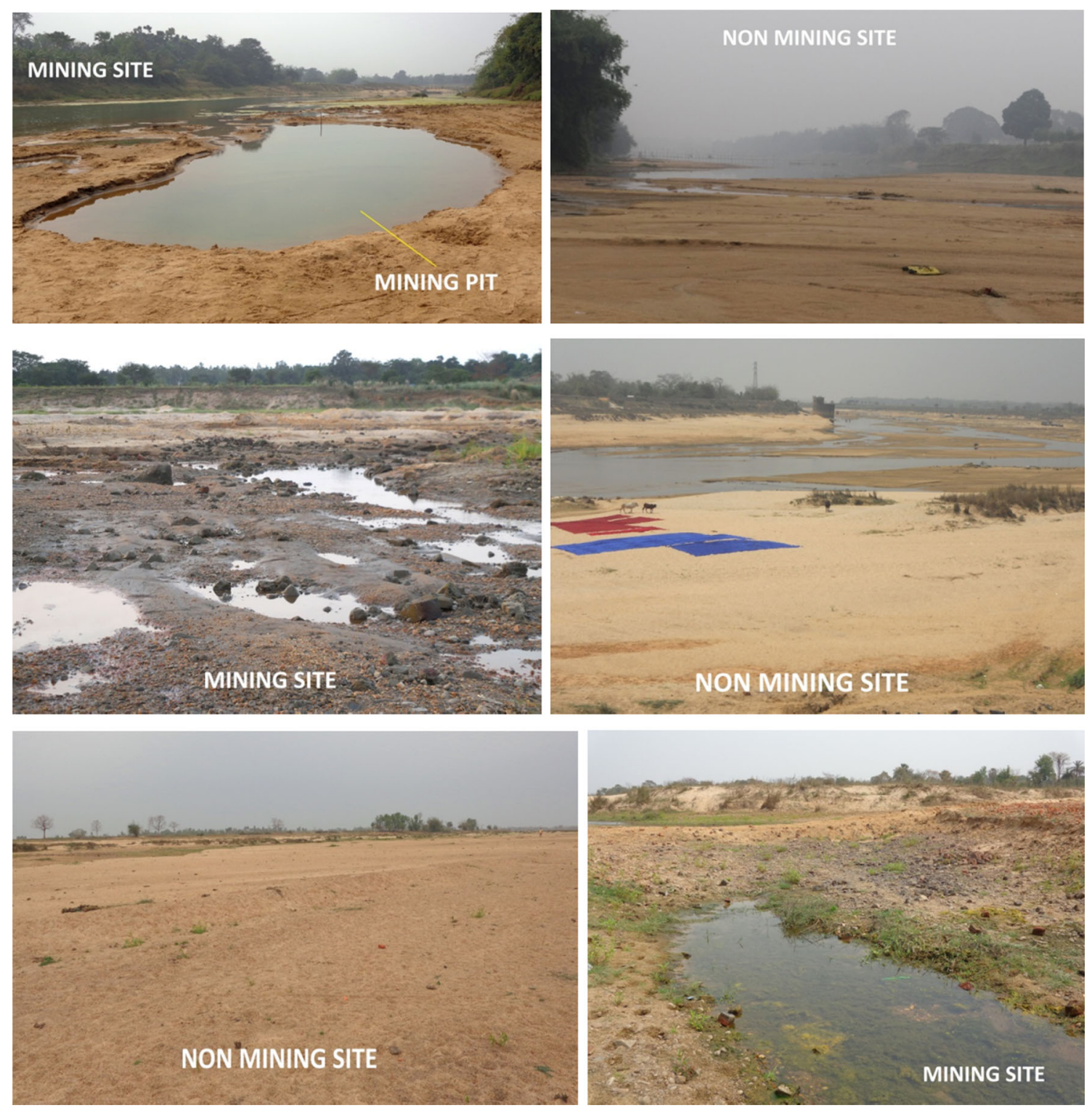

Fig. 3 Sample photographs of mining and non mining site from lower, middle and upper course

Course wise available shear stress during pre-monsoon and monsoon is calculated by DuBoys equation:

DuBoys shear stress equation $\mathrm{I}^{=}$ógds

where ó is the water density $\left(1.00 \mathrm{~g} / \mathrm{cm}^{3}\right), \mathrm{g}$ is the gravitational acceleration, $d$ is the hydraulic radius $(\mathrm{mv})$ and $\mathrm{s}$ is the slope.

The critical shear stress has been calculated following Shields (1936) formula;

Shields critical shear stress Ícr $=\mathrm{Kg}$ (ós - ó) $\mathrm{D}$

where $\mathrm{K}$ is a constant $(0.045), \mathrm{g}$ is gravitational acceleration, ós is sediment density typically $2.65 \mathrm{gm} / \mathrm{cm}^{3}$ (Knighton 1998) and ó is water density and D is the median grain size in meter.

\section{Result and discussion}

\section{Grain size character}

Mean (MZ)

Average size of sediments is represented by mean and is influenced by the source of supply, transporting medium and the energy conditions of the depositional environment (Visher 1969; Sly et al. 1982). Average kinetic energy, velocity of depositional agent is indicated by mean size (Sahu 1964; Rao et al. 2005; Ramaamohanarao et al. 2003). From the given Table 3, mean grain is coarser during monsoon than pre and post monsoon due to voluminous supply of sediments. Texturally, the sediments of 
Kangsabati River are finer to silt and coarse grained, whereas in lower course the sediments are finer grained to clayey silt (Wolanski 1996). More than $(50 \%)$ of the sediment samples comes under moderate class (value) in Palaspai during post monsoon (Fig. 2c). Rests of the samples are coarse due to low and moderately low energy condition. Remaining finer sediments are mostly deposited at a moderate energy condition during monsoon in Sarenga. Grains of mining sites are represents gradual decrease of range in mean size than non mining sites. The gradual decrease in range of mean size clearly exhibits that the gradual increase in energy condition of fluvial regime towards mining sites.

\section{Sorting (ó 1)}

Standard deviation is expressed by sorting of sediments and it indicates the fluctuations in the kinetic energy or velocity
A

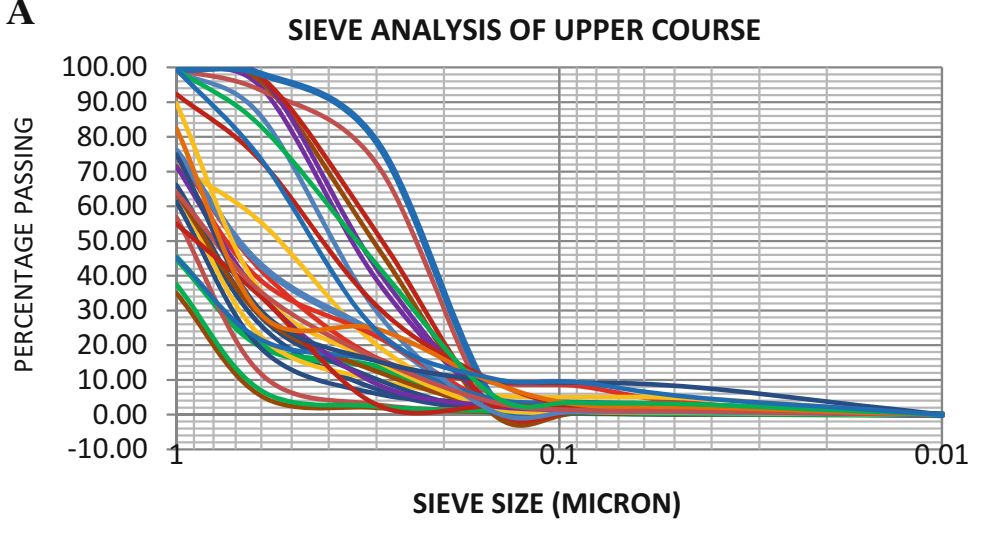

B

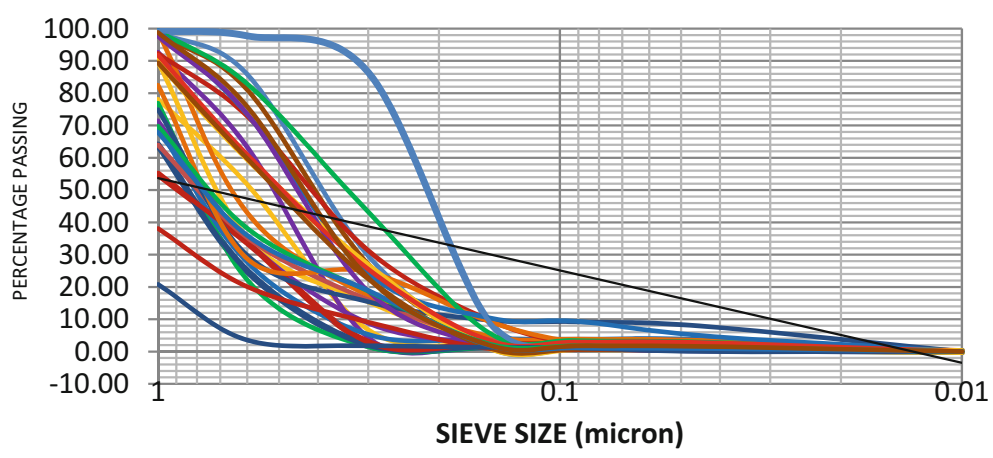

C

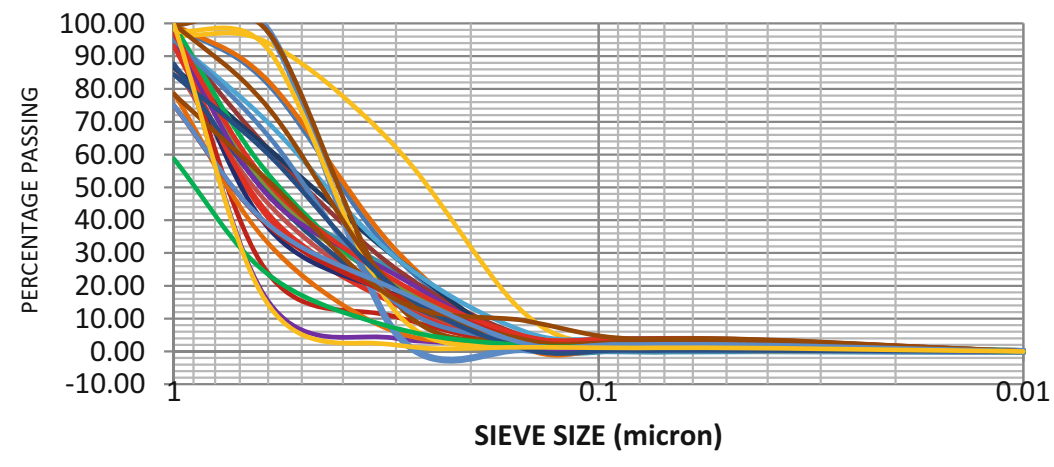

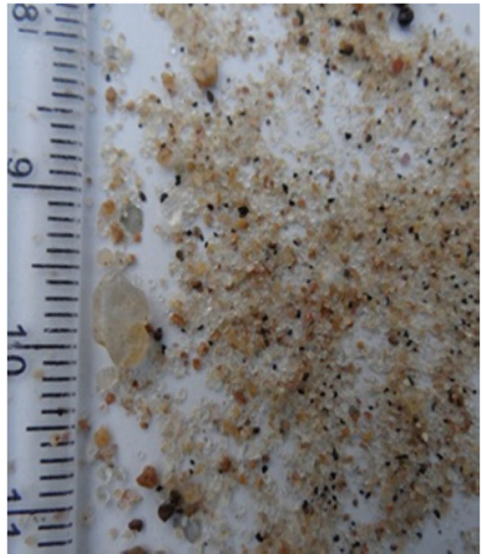
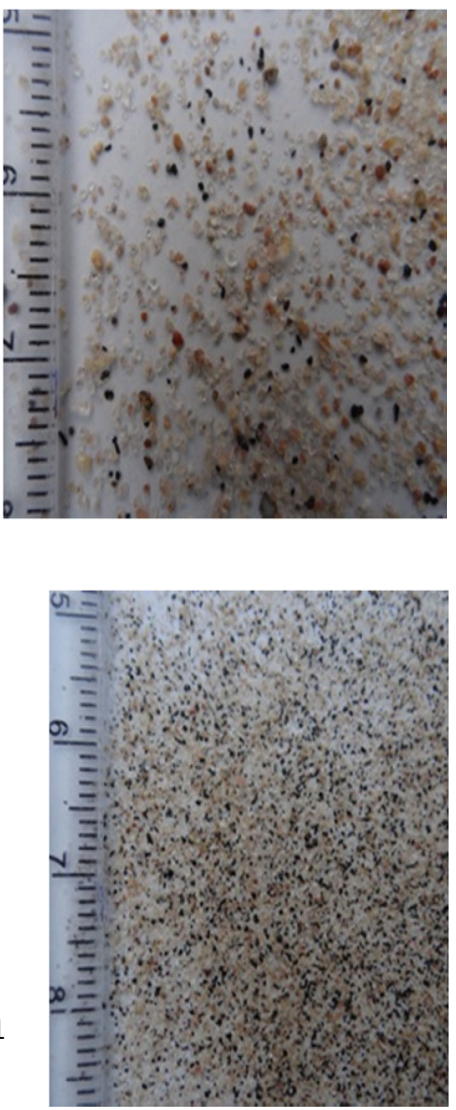

Fig. 4 A Sub angular to sub rounded size in Sarenga. b Subangular quartz grains size in Mohanpur. c Medium grain size in Palaspai 


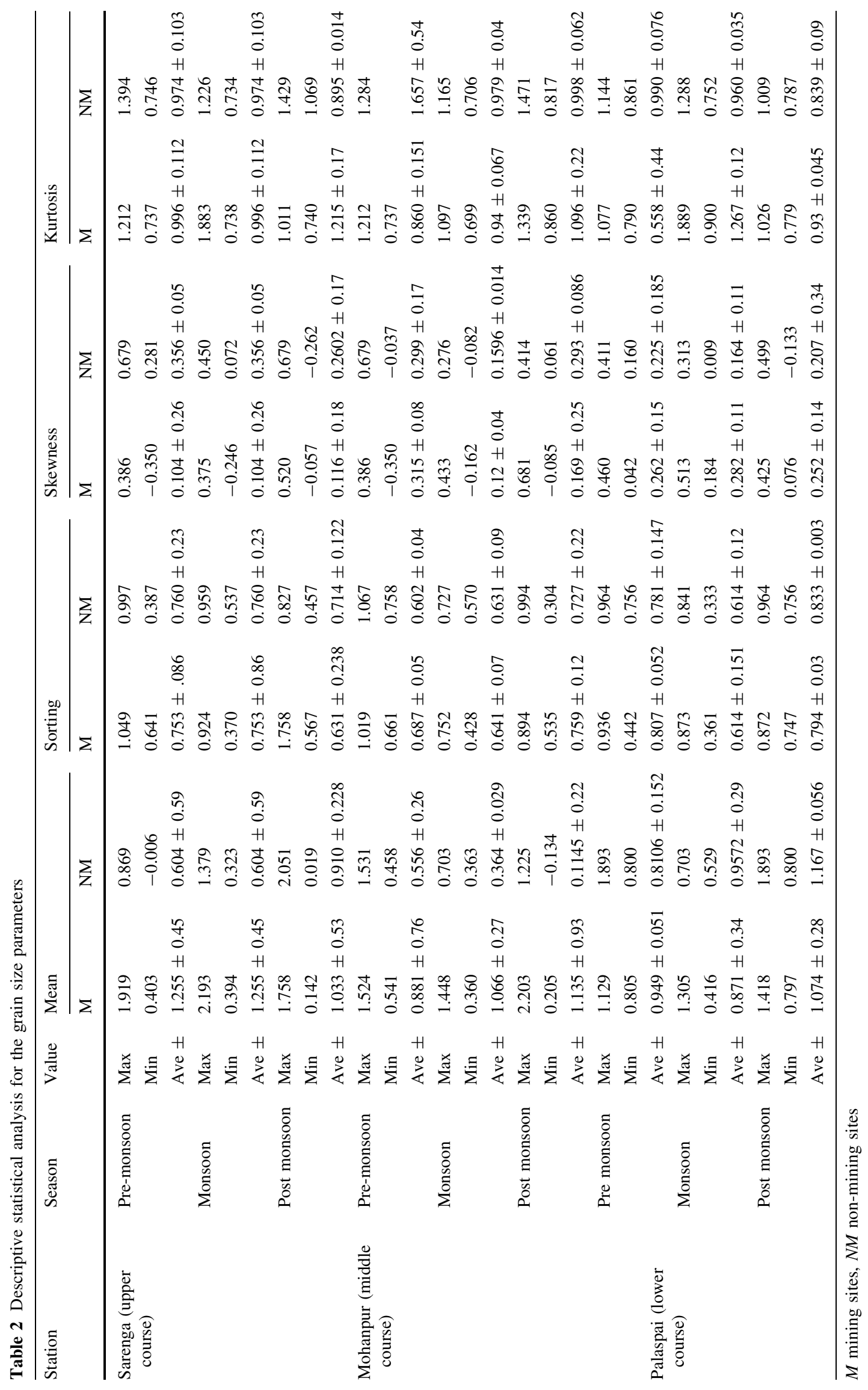


Table 3 Summery of grain size statistical parameters (in percentage of the total number at each station)

\begin{tabular}{|c|c|c|c|c|c|c|c|c|c|}
\hline \multirow[t]{2}{*}{ Textural attributes } & \multicolumn{3}{|c|}{ Sarenga (upper course) } & \multicolumn{3}{|c|}{ Mohanpur (middle course) } & \multicolumn{3}{|c|}{ Palaspai (lower course) } \\
\hline & $\mathrm{P}$ & M & PM & $\mathrm{P}$ & M & PM & $\mathrm{P}$ & M & PM \\
\hline \multicolumn{10}{|l|}{ Mean (Mz) } \\
\hline VCS & 10 & 0 & 0 & 0 & 0 & 10 & 0 & 0 & 0 \\
\hline $\mathrm{CS}$ & 60 & 60 & 70 & 50 & 70 & 40 & 70 & 60 & 50 \\
\hline MS & 30 & 30 & 20 & 50 & 30 & 40 & 30 & 40 & 50 \\
\hline FS & 0 & 10 & 10 & 0 & 0 & 10 & 0 & 0 & 0 \\
\hline \multicolumn{10}{|l|}{ Sorting (ó1) } \\
\hline WS & 10 & 20 & 10 & 0 & 10 & 10 & 10 & 30 & 0 \\
\hline VWS & 0 & 0 & 0 & 0 & 0 & 0 & 0 & 10 & 0 \\
\hline MWS & 40 & 40 & 70 & 10 & 50 & 20 & 20 & 20 & 0 \\
\hline $\mathrm{MdS}$ & 40 & 40 & 20 & 70 & 40 & 70 & 70 & 40 & 100 \\
\hline PS & 10 & 0 & 0 & 20 & 0 & 0 & 0 & 0 & 0 \\
\hline \multicolumn{10}{|l|}{ Skewness (SK1) } \\
\hline VFS & 50 & 40 & 70 & 50 & 10 & 40 & 50 & 30 & 40 \\
\hline FSw & 20 & 20 & 20 & 20 & 50 & 30 & 20 & 40 & 20 \\
\hline$S$ & 20 & 30 & 10 & 30 & 30 & 30 & 30 & 30 & 30 \\
\hline $\mathrm{CS}$ & 10 & 10 & 0 & 0 & 10 & 0 & 0 & 0 & 10 \\
\hline \multicolumn{10}{|l|}{ Kurtosis (KG) } \\
\hline VPK & 0 & 0 & 0 & 0 & 0 & 0 & 0 & 0 & 0 \\
\hline PK & 50 & 50 & 30 & 20 & 30 & 50 & 40 & 30 & 40 \\
\hline MK & 30 & 10 & 40 & 40 & 50 & 20 & 50 & 30 & 60 \\
\hline LK & 20 & 30 & 30 & 40 & 20 & 30 & 10 & 30 & 0 \\
\hline VLK & 0 & 10 & 0 & 0 & 0 & 0 & 0 & 10 & 0 \\
\hline
\end{tabular}

$P$ pre-monsoon monsoon, $P M$ post-monsoon, $C S$ coarse sand, $M S$ Medium sand, $F S$ fine sand, $W S$ well sorted, $M W S$ moderately well sorted, $M d S$ moderately sorted, VFS very fine skew, $F S w$ fine skew, $S$ symmetry, $C S$ course skew, $V P K$ very platykurtic, $P K$ platykurtic, $M K$ mesokurtic, $L K$ leptokurtic, $V L K$ very leptokurtic

conditions of the depositing agent (Sahu 1964). The sorting variation observed to the difference in water turbulence and variability in the velocity of depositing current (Ramanathan et al. 2009; Rajamanickam and Gujar 1985, 1993; Rajamanickam and Muthukrishnan 1995; Angusamy and Rajamanickam 2006). From Table 3, it is observed that most of the sediment are moderately well sorted and moderately sorted during monsoon and post monsoon in Mohanpur, while most of the samples are moderately sorted during post monsoon in Palaspai. Well sorted sediments are highly concentrated during pre monsoon and monsoon season in Sarenga and Mohanpur (Fig. 2a, b). So, coarse sediments tend to show deterioration in sorting whereas fine size grain concentration (Anithamary et al. 2011). Variation of sorting values is high in mining sites (Fig. 3) due to continuous addition of finer/coarser materials in varying proportions.

\section{Skewness (SK1)}

It reflects the symmetry or asymmetry of the frequency distribution of the sediments. Sign of skewness is related to environmental energy. Upper and middle course are dominated by fine to very fine skewed distribution while lower course belongs to equally distributed skewness. Mining sites has more interred changeable skew than nonmining sites due to sediment interruption (Fig. 4). The samples collected from Sarenga and Mohanpur during premonsoon and monsoon are characterized by negative skewness but most of the samples in Palaspai during postmonsoon are positively skewed (Table 2). Coarser sediments (negative skewness) are correlated with higher energy and winnowing action (removal of fines) and finer grained (positive skewness) with low energy levels. In unidirectional transportation process if the sediments are positively skewed and the energy level is low, the sediments get deposited by sheltering effect. This phenomenon is seen in the upper course of River Kangsabati at Sarenga during post monsoon.

\section{Kurtosis $(K G)$}

Kurtosis play a vital role to distinguish sediments in various environments as explained by Duane (1964). It is also functional of internal sorting or distribution. Friedman (1962) suggested that extreme high or low values of 

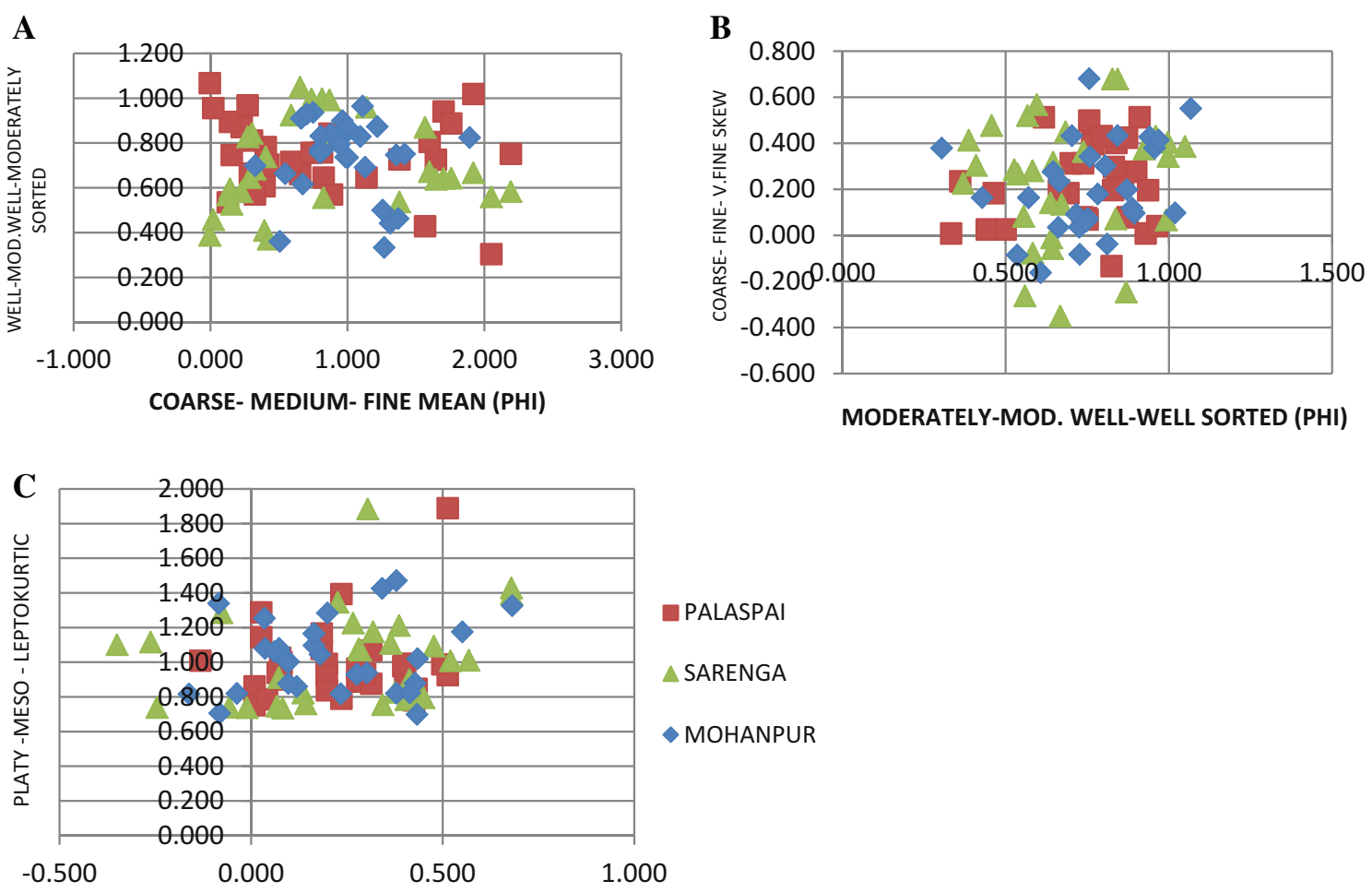

COARSE - SYMMETRY-FINE- VERY FINE SKEWNESS

Fig. 5 Scatter plot showing the bivariate relationship between a Grain size and sorting; b Sorting and skewness; c Skewness and Kurtosis

kurtosis means that part of the sediment achieved its sorting elsewhere in high energy environment. Several kurtosis values reflect the flow characteristics of the depositing medium material (Seralathan and Padmalal 1994; Baruah et al. 1997). Nearly $80 \%$ of the sediments samples are platykurtic and Mesokurtic during premonsoon and monsoon in Palaspai while leptokurtic samples are found in Mohanpur and Sarenga during post monsoon (Table 3). Most of the finer sediments are platykurtic in nature due to aggregation of sediment particle size by compaction process and which results the maturity in the sand.

\section{Bivariate scatter graphs of grain size parameters}

Scatter graphs are measured through bivariate plotting of different grains. It explains certain grain size in relation to energy conditions, medium of transportation, mode of deposition, etc. Bivariate plots are presenting reliability of differences in the fluid flow mechanisms of sediment transportation and deposition (Sutherland and Lee 1994). Relationship between mean grain size and sorting is presented in Fig. 5a. Clustering in medium sized and moderately well sorted grains are found during analysis. Mean grain size and sorting are controlled by stream hydraulics. Sediments are moderately well sorted and very fine skewed towards higher fractions (Fig. 5b). In contrast, moderated well sorted to well sorted sediments are mainly clustered around fine to very fine grain and have negative skewness value. Plotting of skewness against kurtosis is a powerful tool for interpreting the genesis of sediment (Fig. 5c). The result shows that the sediments from upper, middle and lower course of Kangsabati River lie within the negative skewness. Mixing of different graded sediment has one predominant population. But in platykurtic class most of the sediments are slightly positive skewed. Therefore, mixing sands consists of predominant coarser to finer population.

\section{Triangular diagram}

Sediment classification has been done by plotting the percentage of sand, silt and clay in a triangular diagram proposed by Folk 1966. Further, data presentation of sediment samples is simple and facilitates rapid classification of sediments and comparison of samples by Blott and Ply method (2012). In lower course of Kangsabati River, nearly $85 \%$ of the sediment samples are of moderate sand and $15 \%$ samples fall under coarse sand category (Fig. 6d). Maximum coarse sand lies in upper and middle course. The sediment samples of monsoon season are characterized by high proportion of sand than silt and clay. So, particles are medium to finer during pre-monsoon and post-monsoon than in monsoon season. 

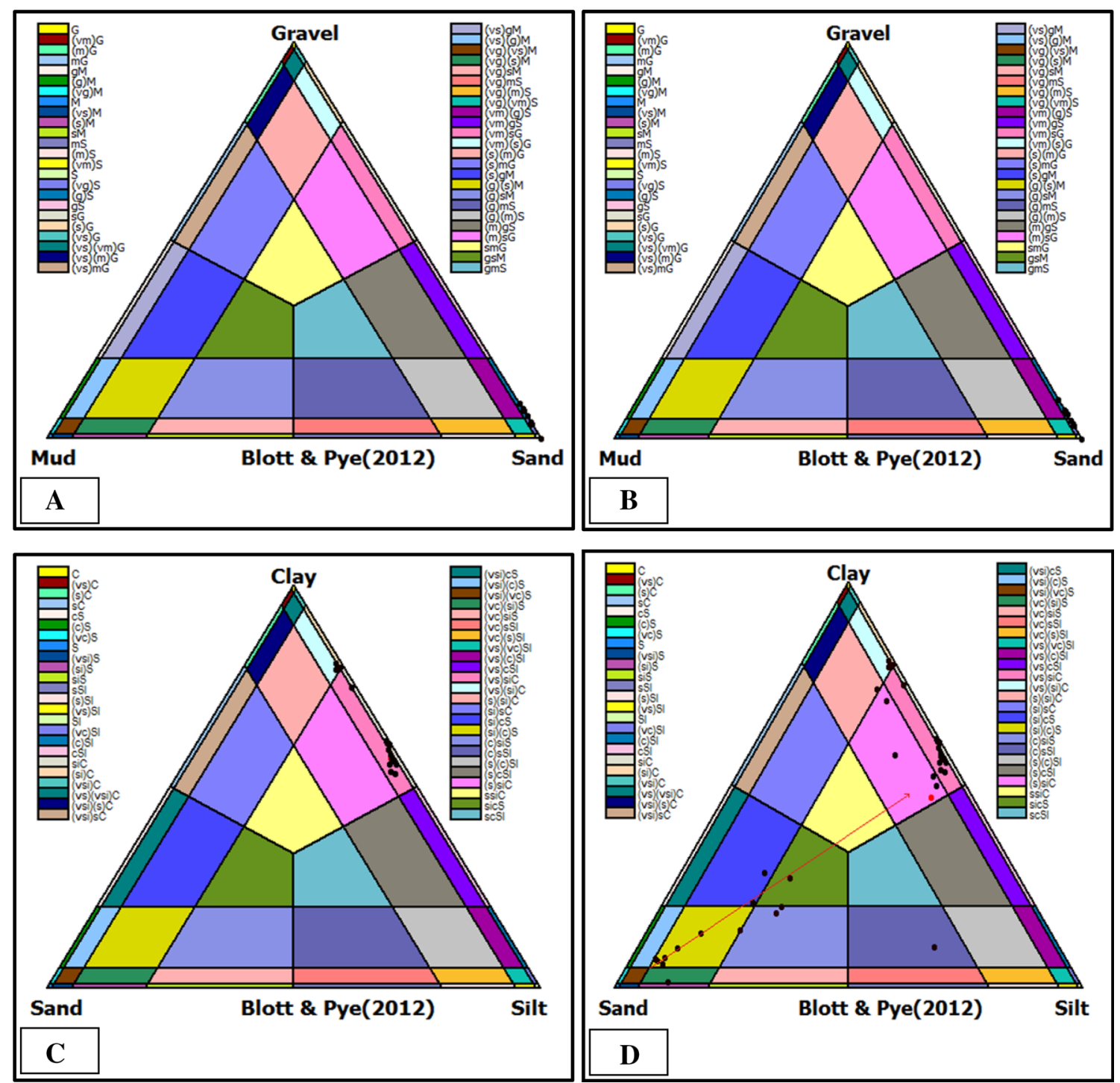

Fig. 6 Triangular diagram showing texture of sediments samples of a Sarenga; b Mohanpur; c Palaspai; d Course wise trend of textural distribution

\section{CM diagram}

First percentile of coarse grain size (C) and median size of sediment samples (M) show the grain size, transporting mechanism and depositional environment in respect to size, range, and energy level of transportation. It also determines process and characteristic agents that are responsible for the formation of fluvial deposits (Passage 1964; Visher 1969). In the present study an attempt has been made to identify the mode of deposition of the sediments in Kangsabati River by CM patterns. First percentile of coarse grain size (C) and Median (M), both are plotted with half phi interval graph of the $\mathrm{C}$ and $\mathrm{M}$, obtained from cumulative curves in microns which represent suspension, saltation and surface creep or rolling modes of transport mechanism. The relation between $\mathrm{C}$ and $\mathrm{M}$ is the effect of sorting by bottom turbulence and shows that entire sample fall tractive current deposits under the suspension and rolling process in Sarenga. In Mohanpur it receives more beaches to tractive current deposit under bottom suspension and rolling process. Whereas tills deposit are accumulated by pelagic suspension process in Palaspai.

\section{Shear stress}

Shear stress plays a crucial role for particles movement or deposition at the river bed. When the shear stress is greater than critical shear stress it reaches to threshold point. This indicates entrainment of sediment, which could potentially result in the degradation of the bed or banks (Buffington and Montagomery 1997; Church 2006; Charlton 2007). In case of shear stress, particles especially gravels are usually 

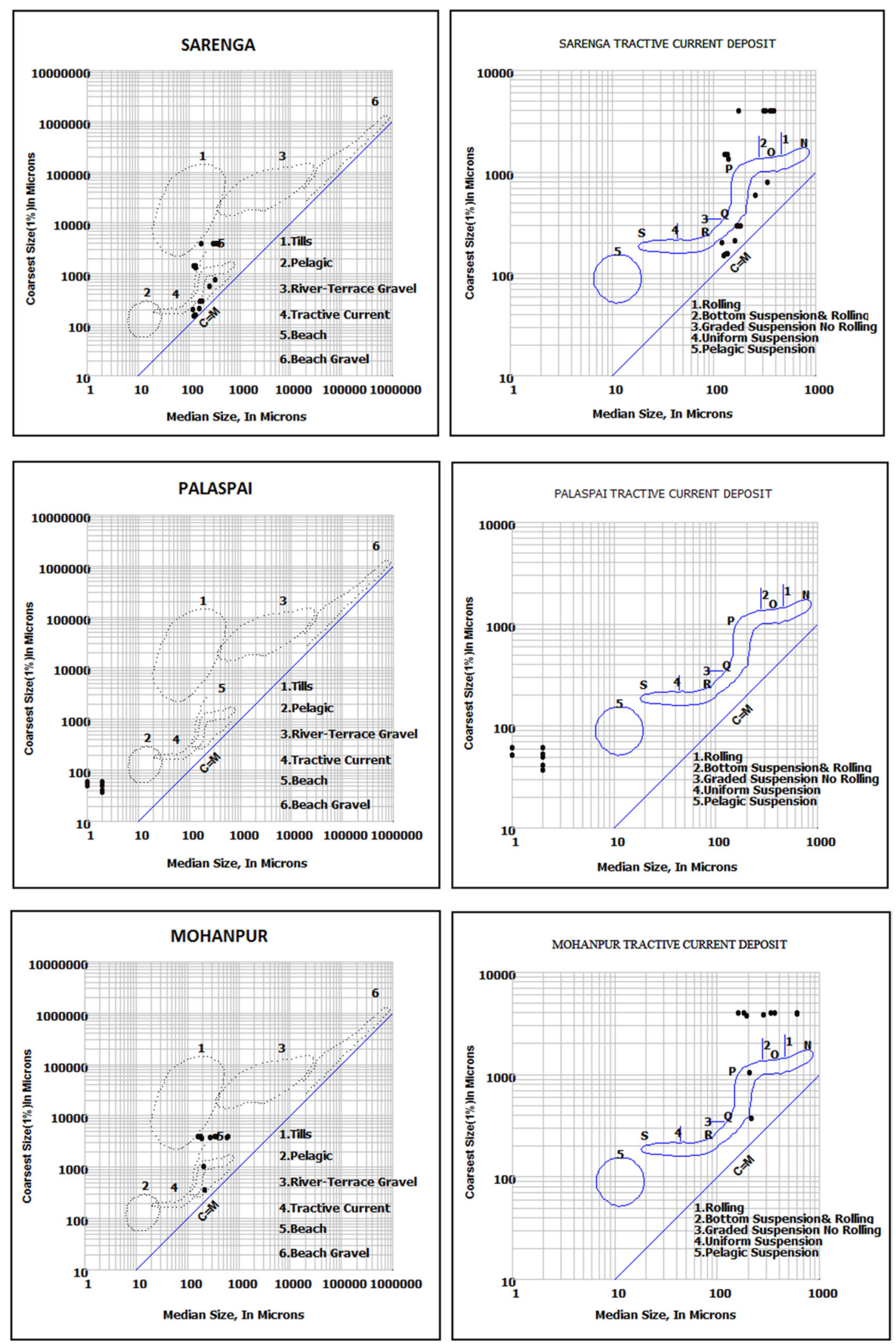

Fig. 7 CM diagrams (Passage 1957, 1964) and Tractive current deposits plot in upper, middle and lower course sites 
deposited in the river bed. But the shear stress of the particles which moving towards, exceeding to the critical shear stress may transport by different ways depending on the flow condition, sediment size, fluid and sediment densities and the other ways of channel conditions (Seetharamaiah 1989). At relatively low shear stress, the particles roll or slide with continuous contact with the bed. Some particles are gradually reduced their size and shear stress, as a result this particles roll or slide with continuous contact with the bed. For further increase in shear stress, some particles are sudden losses the contact with bed and hop or bounce towards the direction of flow (saltation load) but the presence of turbulence fluctuation the reaming particles may go in suspension as well as transported towards downstream (suspended load) (Fig. 7).

Course wise available shear stress and critical shear stress for different grain size for monsoon and pre- monsoon seasons have been calculated (Table 4) and results shows that during pre monsoon and post monsoon in Sarenga, Mohanpur and Palaspai available shear stress is less than critical shear stress. In the lower course of the river, it is affected by pool-riffle alternation process. Shear stress during monsoon is swifter and stronger than post monsoon in Palaspai. During monsoon period (Fig. 8b) the shear stress is more than critical shear stress and a particular grain causing easy landward move. But pre-monsoon shear stress is less than critical shear stress which hinders easy clearance of sediments causing the sedimentation in Mohanpur and Sarenga (Fig. 8a). In case of some sediment samples though the critical shear stress is less than available shear stress but sedimentation happens. It is due to the other factors like sheltering, imbrications, packing of grains, grain fabric effects, adhesion forces and organic mats. Generally critical shear stress for entrainment

Table 4 Available and critical shear stress during pre-monsoon

\begin{tabular}{|c|c|c|c|c|c|c|}
\hline $\begin{array}{l}\text { Sediment } \\
\text { sample }\end{array}$ & $\begin{array}{l}\text { Median } \\
\text { grain size }\end{array}$ & $\begin{array}{l}\text { Water } \\
\text { depth }(m)\end{array}$ & $\begin{array}{l}\text { Water surface } \\
\text { slope }\end{array}$ & $\begin{array}{l}\text { Available shear stress } \\
\left(\mathrm{n} / \mathrm{m}^{2}\right) t=\mathrm{pgds}\end{array}$ & $\begin{array}{l}\text { Criticalshear stress } \\
\left(n / m^{2}\right) t=k g(p s-p) d\end{array}$ & Remarks \\
\hline 1 & 0.00348 & 4.21 & 0.0000094 & 0.3882 & 0.2073 & Erosion \\
\hline 2 & 0.000702 & 3.29 & 0.0000072 & 0.2323 & 0.207 & Erosion \\
\hline 3 & 0.0008365 & 4.01 & 0.0000049 & 0.1927 & 0.4985 & Deposition \\
\hline 4 & 0.0002414 & 2.91 & 0.0000038 & 0.1084 & 0.0967 & Erosion \\
\hline 5 & 0.0003063 & 2.81 & 0.0000067 & 0.1846 & 0.1825 & Erosion \\
\hline 6 & 0.0006746 & 2.99 & 0.0000087 & 0.2551 & 0.402 & Deposition \\
\hline 7 & 0.0006543 & 3.33 & 0.0000081 & 0.2646 & 0.3899 & Deposition \\
\hline 8 & 0.0002487 & 3.17 & 0.0000073 & 0.227 & 0.1482 & Erosion \\
\hline 9 & 0.0004215 & 2.95 & 0.0000075 & 0.217 & 0.5283 & Deposition \\
\hline 10 & 0.0005443 & 3.93 & 0.0000045 & 0.173 & 0.3243 & Deposition \\
\hline 11 & 0.0007499 & 4.15 & 0.0000091 & 0.37 & 0.446 & Deposition \\
\hline 12 & 0.0004265 & 2.12 & 0.0000075 & 0.155 & 0.254 & Deposition \\
\hline 13 & 0.000376 & 2.8 & 0.0000085 & 0.233 & 0.224 & Erosion \\
\hline 14 & 0.0004141 & 2.95 & 0.0000079 & 0.228 & 0.246 & Deposition \\
\hline 15 & 0.0007866 & 1.01 & 0.0000065 & 0.064 & 0.468 & Deposition \\
\hline 16 & 0.0007889 & 1.95 & 0.0000045 & 0.086 & 0.47 & Deposition \\
\hline 17 & 0.000742 & 2.03 & 0.0000066 & 0.1314 & 0.442 & Deposition \\
\hline 18 & 0.0003484 & 3.01 & 0.0000098 & 0.289 & 0.207 & Erosion \\
\hline 19 & 0.0004467 & 3.35 & 0.0000011 & 0.361 & 0.266 & Erosion \\
\hline 20 & 0.00068511 & 2.8 & 0.0000012 & 0.329 & 0.408 & Deposition \\
\hline 21 & 0.0006189 & 7.35 & 0.0000011 & 0.0793 & 0.368 & Deposition \\
\hline 22 & 0.0007175 & 7.09 & 0.0000015 & 0.1043 & 0.427 & Deposition \\
\hline 23 & 0.0004879 & 6.92 & 0.0000017 & 0.1154 & 0.29 & Deposition \\
\hline 24 & 0.0005934 & 5.98 & 0.0000021 & 0.12319 & 0.353 & Deposition \\
\hline 25 & 0.0004498 & 6.02 & 0.00000098 & 0.0578 & 0.268 & Deposition \\
\hline 26 & 0.0005068 & 7.49 & 0.0000015 & 0.1102 & 0.302 & Deposition \\
\hline 27 & 0.0005982 & 8.11 & 0.0000012 & 0.0954 & 0.3565 & Deposition \\
\hline 28 & 0.00008918 & 7.44 & 0.0000012 & 0.0875 & 0.5314 & Deposition \\
\hline 29 & 0.0007138 & 7.62 & 0.0000015 & 0.1121 & 0.4253 & Deposition \\
\hline 30 & 0.0004027 & 7.11 & 0.0000013 & 0.0906 & 0.2399 & Deposition \\
\hline
\end{tabular}


A

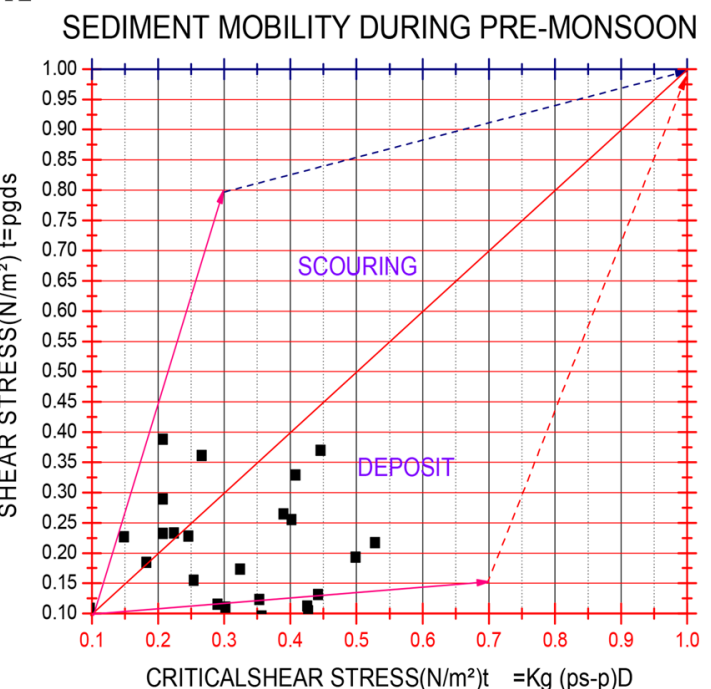

B
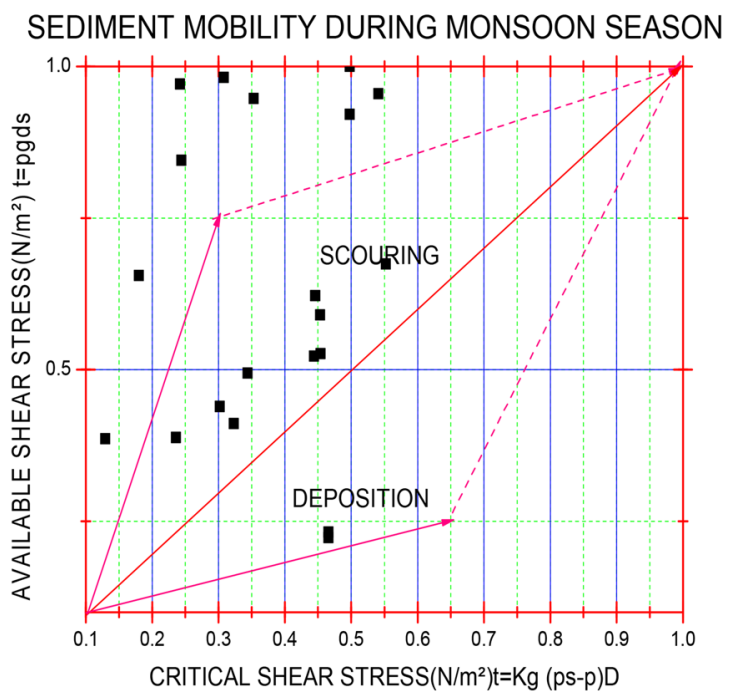

Fig. 8 Available and critical shear stress during monsoon and pre-monsoon of sediment sample

decreases with decrease in grain size but in case of particle sizes less than $0.2 \mathrm{~mm}$, the threshold stress needed for entrainment and are submerged in the laminar sub-layer and therefore, not subject to greater stresses associated with turbulent flow. In poorly sorted sediments resistance may vary across the channel bed depending on the coarseness of the sediments in one region to another, while well sorted sand has a homogenous resistance across the channel. Frictional angle changes with the grain size of the two surrounding grain sizes and sheltered particles may require higher critical shear stress to be entrained.

\section{Conclusion}

Sediment deposits are the result of combined effect of sediment transport and stream hydraulic in connection with the grain size distribution and energy fluctuation between upper course and lower course during pre-monsoon and monsoon seasons. The history of transportation reflects the mode of suspension, rolling and also indicating the complexity in the deposition processes. Most of the sediments are transported by graded suspension and suspension with rolling as indicated by $\mathrm{CM}$ pattern. The granulometric analysis of sediments indicates course wise wide gradation of mean grain size in different seasons. Grain size distribution reveals that most of sediments are coarse in nature, well sorted and very leptokurtic in upper course (Sarenga) while lower course (Palaspai) has mostly medium sand, moderate well sorted and mesokurtic in nature. The sorting behavior indicates that the sediments are transported mostly from upper course during monsoon period. The predominant positive skewness and mesokurtic to leptokurtic nature of the sediments indicate the deposition of sediments in low energy condition and continuous addition of finer or coarser materials and retention of their original characters during deposition. Deficit of available energy than the critical energy to transport a particular grain size during post monsoon is the main reason behind the rapid sedimentation in Mohanpur and Sarenga. The coarse sediments are deposited by higher threshold value of bed mobility in Sarenga while finer particles are deposited due to lower threshold value in Mohanpur and Palaspai. Critical shear stress is higher in Sarenga and gradually decreases in Mohanpur to Palaspai. So, sediment erosion is high in the upper portion of the basin and relatively low in the lower portion.

\section{References}

Al-Saleh S, Khalaf FL (1982) Surface textures of quartz grains from various recent sedimentary environments in Kuwait. Sediment Petrol 52:215-225

Angusamy N, Rajamanickam GV (2006) Depositional environment of sediments along the southern coast of Tamil Nadu, India. Oceanologia 48(1):87-102

Anithamary I, Ramkumar T, Venkatramanam S (2011) Grain size characteristics of the Coleroon estuary sediments, Tamilnadu, East coast of India. Carpathian Earth Environ Sci 6(2):151-157

Annual flood report for the year of 2013: Irrigation and Waterway Directorate. Govt. of West Bengal

Asselman NEM (1999) Grain size trends used to assess the effective discharge for flood plain sedimentation. River Waal, the Netherlands. J Sediment Res 69:51-61

Baruah J, Kotoky, Sharma JN (1997) Textural and geochemical study on river sediments: a case study on the Jhanji River, Assam. J India Assoc Sedimentol 16:195-206

Bhatia MR, Crook KA (1986) Trace element characteristics of graywackes and tectonic setting discrimination of sedimentary basins. Contrib Mineral Petrol 92(2):181-193 
Brambati (1969) Stratigraphy and sedimentation of Siwaliks of North Eastern India. Proc Int Sem Int Basins Geol Res Chiang Mai Thail 427-439

Buffington J, Montagomery D (1997) A Systematic analysis of eight decades of incipient motion studies, with special reference to gravel-bedded rivers. Water Resour Res 33(8):1993-2029

Charlton (2007) Fundamentals of fluvial geomorphology. Rout ledge, New York, p 234

Church M (2006) Bed material transport and the morphology of alluvial river channels. Annu Rev Earth Planet Sci 34:325-354

Clayton J (2010) Local sorting, bend curvature and particle mobility in meandering gravel be rivers. Water Resour Res 46:W02601. doi:10.1029/2008WR007669

Dinesh AC (2009) G-Stat-A Software in VB6 for Grain size Statistical Analyses, CM Diagrams, Trend Diagrams, etc. designed and developed by A.C. Dinesh, Geologist, Marine wing, GSI, Mangalore

Duane DB (1964) Significance of skewness in recent sediments western Pamlico sound, North Carolina. J Sediment Petrol 27(1):3-27

Folk RL (1966) A review of grain-size parameters. Sedimentol 6:73-93

Folk RL, Ward WC (1957) Brazos River bar: a study in the significance of grain size parameters. J Sediment Petrol 27:3-26

Fralick PW, Kronberg BI (1997) Geochemical discrimination of clastic sedimentary. Geology 113:111-124

Friedman GM (1962) On sorting coefficient and log normality of the grain size distribution of sandstones. J Geol 70:737-753

Friedman GM (1967) Dynamic processes and statistical parameters compared for size frequency distribution of beach river sands. J Sediment Petrol 37(2):327-354

Friedman GM (1979) Differences in size distributions of populations of particles among sands of various origins. Sedimentol 26:3-32

Inaman DL (1952) Measures for describing the size distribution sediments. J Sediment Petrol 22(3):125-145

Jain RK, Kothyari UC (2009) Cohesion influences on erosion bed load transport. Water Resour Res 45:17

Knighton D (1998) Fluvial forms and processes: a new perspective. Arnold Publishers, London, p 383

Komar PD (1998) The analysis of grain size measurements by sieving and setting tube techniques. J Sediment Petrol 54:603-614

Leopold (1992) Sediment size that determines channel morphology. In: Billi P et al (eds) Dynamics of gravel bed rivers, Wiley, New York, pp 287-311

Martins LR (1965) Significance of Skewness and Kutosis in environmental interpretation. J Sediment Petrol 35(3):768-770

Moiola RJ, Weiser D (1968) Textural parameters: an evaluation. J Sediment Petrol 38(1):45-53

Mueller E, Pitlick, Nelson J (2005) Variation in the reference shields stress for bed load transport. Water Resour Res 41:1-10

Mukhopadhyay S (1992) Terrain analysis of river basin. Vora publication, Delhi

Nair MNM, Ramachandran KK (2002) Textural and trace elemental distribution in sediments of the Beypore estuary (SW coast of India) and adjoining innershelf. Indian J Mar Sci 31:295-304
Passage R (1957) Textural as characteristics of clastic deposition. Bull Am Assoc Petrol Geol 41:1952-1984

Passage R (1964) Grain size representation by CM Patterns as a Geological tool. J Sediment Petrol 34(4):830-847

Poppe LJ, Elison AH (2007) A visual basic program to plot sediment grain size data on ternary diagrams. Comput Geosci 34:561-565

Rajamanickam GV, Gujar AR (1985) Indications given by median distribution and $\mathrm{CM}$ patterns on clastic sedimentation in Kalbadevi, Mirya and Ratnagiribays, Maharashtra, India. Giorn Geol 47:237-251

Rajamanickam, Gujar (1993) Depositional processes inferred from the $\log$ probability distribution. In: Jhingram V (ed) Recent researches in sedimentology. Hindustan publishing Corporation, Delhi, pp 154-164

Rajamanickam GV, Muthukrishnan N (1995) Grain size distribution in the Gadilam river basin, northern Tamil Nadu. J Indian Assoc Sedimentol 14(1\&2):55-66

Ramaamohanarao $T$, Sairam K, Venkateswararao $Y$, Nagamalleswararao B, Viswanath K (2003) Sediment logical characteristics and depositional environment of Upper Gondwana rocks in the Chintalapudi sub basin of the Godavari valley, Andhra Pradesh, India. J Asian Earth Sci 21:691-703

Ramanathan AL, Rajkumar K, Majumder J, Sing G, Behara PN, Santra SC, Chidambaram S (2009) Textural characteristics of the surface sediments of a tropical mangrove Sundarban ecosystem India. India J Mar Sci 38(4):397-403

Rao PS, Ramaswamy V, Thwin S (2005) Sediment texture, distribution and transport on the Ayeyarwady continental shelf, Andaman Sea. Mar Geol 216(4):139-247

Sahu BK (1964) Depositional mechanism from the size analysis of clastic sediments. J Sediment Petrol 34(1):73-83

Seetharamaiah J (1989) Studies on modern deltaic sediments of the Penner River, East Coast of India Ph.D. Thesis submitted to Andhra University, Waltair (Unpublished)

Seralathan, Padmalal (1994) Textural studies of surface sediments of Muvattupvzha River and central Vembanand estuary, Kerala. J Geol Soc India 43(2):179-190

Sly PG, Thomas RL, Pelletier BR (1982) Comparison of sediment energy-Texture relationships in marine and lacustrine environments. Hydrobiologia 91:71-84

Sutherland RA, Lee C (1994) Discrimination between coastal sub environments using textural characteristics. Sedimentology 41:1133-1145

Visher GS (1969) Grain size distributions and depositional processes. J Sediment Petrol 39(3):1074-1106

Wai OW, Wang CH, Li YS, Li XD (2004) The formation mechanisms of turbidity maximum in the Pearl River estuary, China. Mar Pollut Bull 48(5):441-448

Wiberg PL, Smith DJ (1987) Calculations of the critical shear stress for motion of uniform and heterogeneous sediments. Water Resour Res 23(8):1471-1480

Wolanski E, Huan NM, Dao LT, Nahn NH, Thuy NN (1996) Finesediment dynamics in the Mekong River Estuary, Vietnam. Estuar Coast Shelf Sci 43:565-582 